\title{
Quorum sensing: implications on Rhamnolipid biosurfactant production
}

\author{
DEVENDRA H. DUSANE ${ }^{1}$, SMITA S. ZINJARDE ${ }^{1}$, VAYALAM P. \\ VENUGOPALAN ${ }^{2}$, ROBERT J.C. MCLEAN ${ }^{3}$, MARY M. WEBER ${ }^{3}$ AND \\ PATTANATHU K.S.M. RAHMAN ${ }^{4 *}$
}

${ }^{1}$ Institute of Bioinformatics and Biotechnology, University of Pune, Pune-411 007 India, ${ }^{2}$ Biofouling and Biofilm Processes Section, Water and Steam Chemistry Division, BARC Facilities, Kalpakkam-603 102 India, ${ }^{3}$ Department of Biology, Texas State University-San Marcos, 601 University Drive, San Marcos, TX 78666, USA and ${ }^{4}$ Chemical and Bioprocess Engineering Group, School of Science and Engineering, Teesside University, Middlesbrough-TS13BA, UK

\begin{abstract}
Quorum sensing (QS) has received significant attention in the past few decades. QS describes population density dependent cell to cell communication in bacteria using diffusible signal molecules. These signal molecules produced by bacterial cells, regulate various physiological processes important for social behavior and pathogenesis. One such process regulated by quorum sensing molecules is the production of a biosurfactant, rhamnolipid. Rhamnolipids are important microbially derived surface active agents produced by Pseudomonas spp. under the control of two interrelated quorum sensing systems; namely las and $r h l$. Rhamnolipids possess antibacterial, antifungal and antiviral properties. They are important in motility, cell to cell interactions, cellular differentiation and formation of water channels that

*To whom correspondence may be addressed (p.rahman@tees.ac.uk)

Abbreviations: QS: quorum sensing; AI: autoinducer; HSL: homoserine lactone; AHL: acyl homoserine lactone; PQS: pseudomonas quinolone signal; sRNA: small ribonucleic acid; RL: rhamnolipid; HAA: 3-(3-hydroxyalkanoyloxy) alkanoic acid; CTAB: cetyl trimethyl ammonium bromide; TLC: thin layer chromatography; GC: gas chromatography; MS: mass spectroscopy; FTIR: fourier transform infrared spectroscopy; ATR: attenuated total reflectance; NMR: nuclear magnetic resonance; SDS: sodium dodecyl sulfate; CMC: critical micelle concentration; LPS: lipopolysaccharide; TMV: tobacco mosaic virus; PAI: pseudomonas autoinducer; FAD: flavin adenine dinucleotide; NAD: nicotinamide adenine dinucleotide; TDP: thiamine di-phosphate; $\mathrm{mN} / \mathrm{m}$ : milli-Newton per meter
\end{abstract}


are characteristics of Pseudomonas biofilms. Rhamnolipids have biotechnological applications in the uptake of hydrophobic substrates, bioremediation of contaminated soils and polluted waters. Rhamnolipid biosurfactants are biodegradable as compared to chemical surfactants and hence are more preferred in environmental applications. In this review, we examine the biochemical and genetic mechanism of rhamnolipid production by P. aeruginosa and propose the application of QS signal molecules in enhancing the rhamnolipid production.

\section{Introduction}

Quorum sensing (QS) is the mechanism by which bacteria engage in cell-to-cell communication using diffusible molecules based on a critical cell density (Williams et al., 2007). When the cell density increases these molecules referred to variously as autoinducers (Fuqua et al., 1997, Kleerebezem et al., 1997, Williams and Camara, 2009), pheromones or quoromones are produced that dictate the behavior of bacterial populations. QS signaling molecules, control diverse physiological processes; some of which are inter-related and under the control of multifaceted QS systems. For instance, in P. aeruginosa, exo-polysaccharide production (Davies et al., 1998), antibiotic resistance (Bjarnsholt et al., 2005) and biofilm formation (Davies et al., 1998, Hentzer et al., 2001) are all under the control of QS molecules. In addition to the aforementioned examples, certain Pseudomonas sp. also produces a surface active agent, viz. rhamnolipid, the production of which is regulated by QS molecules (Pearson et al., 1997).

Rhamnolipids have been extensively studied due to their antibacterial, antifungal and antiviral properties (Haferburg et al., 1987, Stanghellini and Miller, 1997, Syldatk et al., 1985). They are important in bacterial cell motility, cell to cell interactions, cellular differentiation and formation of water channels that are characteristics of Pseudomonas biofilms. Rhamnolipids also enable Pseudomonas spp. to access poorly soluble hydrophobic carbon sources and thereby facilitate their uptake (Maier and Soberon-Chavez, 2000, Nealson et al., 1970). These properties have encouraged the use of rhamnolipid compounds in environmental bioremediation of contaminated soils and polluted waters. In the medical scenario, they are important as antimicrobials, healing of wounds and in organ transplants (Tatjana and Goran, 2007). Apart from the above applications, rhamnolipids are also used in cosmetics, pesticide removal, pharmaceutical, oil sludge recovery, enhanced oil recovery, household cleaning, agriculture and food industry. Morever, rhamnolipids are biodegradable and less toxic than many synthetic surfactants, and hence their use is highly favored (Hommel, 1990, Volkering et al., 1995).

In this review, we will focus on quorum sensing in detail and describe its role in rhamnolipid production, with particular reference to Pseudomonas aeruginosa. The role of quorum signaling in rhamnolipid biosynthesis, bacterial physiology and ecology is described. We have also discussed the application of quorum signaling molecules in enhancing the production of rhamnolipids. 


\section{Quorum Sensing}

QUORUM SENSING MOLECULES

Quorum sensing has received a great deal of attention, primarily due to the diverse roles it plays in regulating bacterial physiology (Miller and Bassler, 2001, Waters and Bassler, 2005). QS implies that bacteria sense each other by detecting a threshold accumulation of the secreted signals. The signal molecules are well documented in both Gram positive and Gram negative bacterial species. However, there seems to be a significant difference in the signal molecules amongst these bacterial groups. In the Gram-positive bacteria, QS is associated with a number of linear and posttranslationally modified peptide based signal molecules, such as the peptide lactones and peptide thiolactones which are found in Bacillus subtilis, Enterococcus spp., and Staphylococcus aureus. The chemical structures of the Gram-positive QS peptides vary greatly in the number of residues and the type of modifications. The biosynthesis pathways are however more complex in Gram-positive bacteria than the AHL molecules in Gram-negative bacteria, because of the post translational modifications of the peptides and their inability to diffuse across the membranes. Interestingly, to date the largest studied most complex peptide signal molecules produced by a few Grampositive bacterial species are the lantibiotics. These molecules possess antimicrobial activity, as shown by nisin produced by Lactobactococcus lactis (Lubelski et al., 2008). Another emerging class of compounds in Staphylococcus aureus; Enterococcus faecalis; Listeria monocytogenes and other Staphylococci are the type I autoinducing peptide. These QS molecules play an important role in the Gram-positive bacterial physiology (Miller and Bassler, 2001, Waters and Bassler, 2005).

In Gram-negative bacteria, the regulation of quorum sensing is under the control of the autoinducer (AI) molecules. These AI molecules belong to the biochemical class of acyl homoserine lactones, which are lipophilic in nature. Homoserine lactones are derived from S-adenosyl-methionine, which is one of the substrates for AHL synthesis and consists of a hydrophilic homoserine lactone head group and a hydrophobic acyl side chain that varies based on species. The side chain ranges from 4 to 18 carbons, with the most significant divergence in length and chemical composition occurring at the third carbon. These alterations in structure act to provide specificity to QS signals and facilitate communication between bacteria. The quorum sensing molecule, designated as autoinducer 1 (AI-1), includes Lux based quorum sensing systems present in Gram-negative bacteria such as Agrobacterium tumefaciens, Pseudomonas aeruginosa and Vibrio fischeri (Engebrecht et al., 1983, Fuqua et al., 1994). Quorum sensing was first characterized in the marine bacteria Vibrio harveyi and Vibrio fischeri (Nealson et al., 1970, Nealson and Hastings, 1979). In V. harveyi, there are two types of densitydependent signaling systems that regulate bioluminescence activity consisting of autoinducer 1 and 2. The AI-1 (N-3-oxohexanoyl-L-homoserine lactone) molecule found in V. fischeri governs the induction of luminescence operon (Gilson et al., 1995). $V$. harveyi and V. cholerae have been reported to use the AI-1 quorum sensing circuit for intra-species communication. The essential characteristics of AI-1 systems are the biosynthesis of acylated homoserine lactones (AHLs) by an AHL synthase, encoded by luxI in V. fischeri or luxI homologs in other bacteria; and an AHL response regula- 
tor, encoded by luxR (or luxR homologs). The N-octanoyl-L-homoserine lactone (AI-1) molecule in $V$. fischeri interacts with and activates the luminescence in E. coli via LuxR (Gilson et al., 1995). The other QS signal molecules designated as autoinducer 2 (AI-2) is observed in both Gram-negative and Gram-positive bacterial species and is suggested to mediate communication among and between species (Bassler et al., 1997, Schauder et al., 2001). AI-2 signal production occurs in bacteria that possess a luxS homologue. The AI-2 molecule in Vibrio harveyi is currently believed to be furanosyl borate diesters (Chen et al., 2002). Several other bacterial species can interact with the Vibrio harveyi AI-2 signaling pathway and the AI-2 modifying LuxS protein sequence is extremely conserved throughout the bacterial kingdom. The third type of autoinducer (AI-3) molecules are involved in cross talk and inter-kingdom signaling with the eukaryotic hormones (epinephrine/ norepinephrine). The AI-3 molecules are observed in E. coli O157:H7 and the host epinephrine cell signaling. This signaling activates transcription of virulence genes in enterohemorrhagic $E$. coli $\mathrm{O} 157: \mathrm{H} 7$ as well as intestinal cell actin rearrangement. The structure of AI-3 molecules is however yet not elucidated.

Apart from these autoinducer molecules, other non-AHL compounds such as indole, PQS, small RNA and secondary messengers are also involved in quorum sensing induction. Indole is produced and is reported to act as an extracellular signal in the induction of quorum in E. coli (Wang et al., 2005). Another molecule heptyl-hydroxyquinolone, designated the Pseudomonas quinolone signal (PQS) found exclusively in Pseudomonas spp. is a part of the quorum sensing hierarchy. PQS acts as a link between las and rhl systems (McKnight et al., 2000). PQS is similar to AHLs with respect to size and its lipophilic nature. Most of the genes involved in the synthesis and regulation of PQS have been described in detail earlier, however the mechanism of activity is unknown (Cao et al., 2001, Deziel et al., 2004, Diggle et al., 2003, Gallagher et al., 2002). These molecules diffuse freely through the bacterial membrane and are internally sensed. Other molecules, such as the small RNAs also play a role in quorum sensing. It is becoming increasingly apparent that like other bacterial processes, integration of information by QS systems is regulated by noncoding small RNAs (sRNAs). These sRNAs are global regulators that act directly or indirectly to control gene expression by post-transcriptional mechanisms. sRNAs are important regulators involved in bacterial and eukaryotic developmental processes (Masse et al., 2003, Wienholds and Plasterk, 2005). Bejerano-Sagie and Xavier (2007) have recently reviewed the crucial role of small noncoding RNAs in the regulation of bacterial QS. Regulation by sRNAs rather than by proteins is presumed to be beneficial when a rapid response is required, because of the short time required to synthesize or degrade sRNAs compared with synthesizing and degrading proteins.

QS systems govern a diverse set of microbial processes, including antibiotic biosynthesis, swarming, swimming and twitching motility, plasmid conjugal transfer, biofilm formation (Davies et al., 1998), pathogenesis, production of biosurfactant, enzymes and other secondary metabolites (for reviews see Camara et al., 2002, Fuqua and Greenberg, 2002, Lazdunski et al., 2004, Miller and Bassler, 2004, Pappas et al., 2004, Whitehead et al., 2001). Recently, the study of QS systems has been extended to include implications in synthetic biology for population control (You et al., 2004), band detection (Basu et al., 2005) and predator-prey systems (Balagadde et al., 2008). In this review, we focus especially on the aspects of QS involved in the production of rhamnolipid. 


\section{QUORUM SENSING IN MICROBIAL COMMUNITIES}

QS activities have been documented in biofilms for some time (Davies et al., 1998, McLean et al., 1997), although the magnitude of their role in biofilms depends on the nutritional environment (Shrout et al., 2006). As stated earlier, P. aeruginosa has several QS systems, including the AHL-mediated las and $r h l$ systems, the PQS system (Mashburn and Whiteley, 2005); as well as the AI-2 QS system (Duan et al., 2003). Very recently, small regulatory RNA molecules have also been shown to influence QS regulation (Tu et al., 2008). These signals and many of the functions that they encode are quite important for biofilm development and bacterial interactions within microbial communities (Givskov et al., 1996, Parsek and Greenberg, 2000). Several years ago, Singh et al. (2000) investigated the AHL expression levels in planktonic and biofilm grown $P$. aeruginosa. They found that the ratio of 3-oxo-dodecanoyl homoserine lactone (3-oxo-C12 HSL, produced by the lasI gene product) to N-butanoyl homoserine lactone (C4 HSL, produced by the rhlI gene product) in planktonic populations was approximately $3: 1$. In laboratory-grown and clinically-obtained biofilms (sputum samples of cystic fibrosis patients), the ratio was reversed with C4-HSL being the predominant AHL (Singh et al., 2000). Among other things, C4-HSL regulates rhamnolipid biosynthesis (Ochsner and Reiser, 1995). Here, we focus on biofilm and microbial community features that are influenced by rhamnolipids.

Rhamnolipids function as biosurfactant molecules (Davey et al., 2003). In this fashion they have been predicted to facilitate uptake of poorly soluble, hydrophobic compounds. Work from the laboratories of PA Holden (2002) and RM Miller (1994, 1995) have shown the emulsifying nature of rhamnolipids that enables Pseudomonas sp to facilitate hydrocarbon utilization. Interestingly, one study showed that the $P$. aeruginosa outer membrane was removed in the presence of rhamnolipids, such that the hydrophobic membrane interior could bind directly to lipids (Al-Tahhan et al., 2000).

During the process of biofilm development and maturation, surface-attached cells will aggregate into microcolonies that are surrounded by regions of few cells referred to as water channels (Davey and O'Toole, 2000, Sauer et al., 2002). During the aggregation process, surface-colonized $P$. aeruginosa move across the substratum by a combination of twitching motility, which involves type IV pili (O'Toole and Kolter, 1998); and swarming, which involves cell elongation, hyper-flagellation and differentiation (Kohler et al., 2000). Rhamnolipids play a role in the swarming process, acting both as surface wetting agents and as chemotaxis stimuli. In swarming but not swimming, rhamnolipids function as chemoattractants whereas the chemically related, hydroxy alkanoic acids function as chemorepellants (Tremblay et al., 2007). Swarming can be blocked by branched chain fatty acids, which presumably compete with rhamnolipids (Inoue et al., 2008).

Rhamnolipids are also important for the formation of water channels in mature biofilms as shown by Davey et al. (2003). During this study, rhl mutants, unable to synthesize rhamnolipids, formed biofilms lacking the characteristic architecture (micro-colonies and water channels). Co-culture of the $r h l$ mutants with wild type Pseudomonas could partially rescue the biofilm structural phenotype. Overproduction of rhamnolipids caused an inhibition of biofilm formation, blocked cellular aggregation, and also blocked secondary colonization onto preformed biofilms by other 
planktonic bacteria (Davey et al., 2003). Rhamnolipids have also been associated with cell dispersal from biofilms (Boles et al., 2005, Pamp and Tolker, 2007).

One notable feature of biofilms is the protection that is offered to their component cells from antimicrobial agents and external forces including predation and the immune system (Costerton et al., 1987). Rhamnolipids do play a role in the chemical ecology of biofilms. Rhamnolipid production within $P$. aeruginosa biofilms has been shown to cause the rapid killing of polymorphonuclear leukocytes during experimental lung infections of mice (Jensen et al., 2007). From a microbial competition perspective, rhamnolipids, produced by $P$. aeruginosa have been shown to be able to disrupt preformed biofilms of Bordetella bronchiseptica (Irie et al., 2005). Production of these biosurfactants is not always beneficial to $P$. aeruginosa. Kohler et al. (2007) showed that the action of the antibiotic, azithromycin, was enhanced in the presence of rhamnolipids, presumably as these compounds facilitated the transport of the antibiotic across the bacterial membrane. Although they do have varied roles within biofilms (Pamp and Tolker, 2007), rhamnolipids are an important component of Pseudomonas biofilm development, structure, and functions.

\section{Biosurfactant}

Biosurfactants are surface active agents that have been receiving increasing attention on account of their unique properties such as their mild production conditions, lower toxicity, and higher biodegradability, compared to their synthetic chemical counterparts (Rosenberg and Ron, 1999). Biosurfactants are produced by bacteria or yeasts from variety of sources such as sugars, glycerol, oils etc. Biosurfactants are classified as glycolipids, lipopeptides, phospholipids, fatty acids, neutral lipids, and polymeric or particulate compounds (Desai and Banat, 1997). The hydrophobic portion of the molecule may be long-chain fatty acids, hydroxyl fatty acids or $\alpha$-alkyl- $\beta$-hydroxyl fatty acids. The hydrophilic moiety can be a carbohydrate, amino acid, cyclic peptide, phosphate, carboxylic acid or alcohol. One such biosurfactants that have been extensively studied is rhamnolipid (Lang and Wullbrandt, 1999).

\section{RHAMNOLIPID BIOSURFACTANT}

Rhamnolipid production is a characteristic of $P$. aeruginosa and was first described by Jarvis and Johnson (1949), however recently other pseudomonads. P. putida and P. chlororaphis, as well as Burkholderia pseudomallei have been reported to produce a variety of rhamnolipids (Gunther et al., 2005, Haussler et al., 1998, 2003, Tuleva et al., 2002). The production of rhamnolipids is species specific. Some species produce a mono-rhamnolipid, others produce a di-rhamnolipid and yet others produce a mixture of rhamnolipids, all of which vary in lipid chain lengths. The rhamnolipids are composed of a polar head group and one or more non-polar tail. P. aeruginosa produces four types of rhamnolipids, including a mixture of homologous species of RL1 $\left(\mathrm{RhC}_{10} \mathrm{C}_{10}\right)$, RL2 $\left(\mathrm{RhC}_{10}\right), \mathrm{RL} 3\left(\mathrm{Rh}_{2} \mathrm{C}_{10} \mathrm{C}_{10}\right)$ and $\mathrm{RL} 4\left(\mathrm{Rh}_{2} \mathrm{C}_{10}\right)$ (Rahman et $a l ., 2002)$. The length of the carbon chains found on the $\beta$-hydroxy portion of the rhamnolipid can vary significantly; however, in case of $P$. aeruginosa ten carbon molecule chains are the predominant form (Deziel et al., 2000). Rhamnolipid as 
well as their precursor, 3-(3-hydroxyalkanoyloxy) alkanoic acids (HAAs), display tensioactive properties (Deziel et al., 2003), which further facilitate their medical, environmental and industrial applications. Rhamnolipid induces a remarkably larger reduction in the surface tension of water from $72 \mathrm{mN} / \mathrm{m}$ to values below $30 \mathrm{mN} / \mathrm{m}$ and it also reduces the interfacial tension of water/oil systems from $43 \mathrm{mN} / \mathrm{m}$ to values below $1 \mathrm{mN} / \mathrm{m}$. Rhamnolipids also show an excellent emulsifying activity with a variety of hydrocarbons and vegetable oils (Abalos et al., 2001). Rhamnolipids solubilize hydrophobic molecules, such as long-chain hydrocarbons, and allow their use as a carbon source and in addition facilitate the interactions between cells by promoting aggregation (Herman et al., 1997).

Rhamnolipids are extensively used in the production of fine chemicals, characterization of surfaces and surface coatings, as additives for environmental remediation and as biological control agents (Stanghellini and Miller, 1997). Rhamnolipids have been regarded as virulence factors (Kownatzki et al., 1987) and antimicrobials (Abalos et al., 2001), and are implicated in the development of biofilms (Davey et al., 2003) and along with HAAs, have been documented to be crucial for $P$. aeruginosa swarming motility (Deziel et al., 2003, Kohler et al., 2000).

\section{METHODS FOR RHAMNOLIPID DETECTION AND QUANTIFICATION}

In the last few decades, extensive research has been conducted in the area of biosurfactants. This has lead to the development of various techniques to detect, quantify and enhance the production of biosurfactants. Various techniques, especially with respect to rhamnolipid biosurfactant, are mentioned here. Each of these methods has been described in a recent review by Heyd et al. (2008) and other references stated below.

i. Surface tension reduction (Guerra-Santos et al., 1984, Haussler et al., 1998).

ii. Hemolytic activity (Siegmund and Wagner, 1991).

iii. Colorimetric method using Cetyl Trimethyl Ammonium Bromide (CTAB) plate assay (Siegmund and Wagner, 1991).

iv. Methylene blue complexation method (Pinzon and Ju, 2009).

v. Rhamnolipid estimation using Anthrone reagent (Helbert and Brown, 1957).

vi. Rhamnolipid estimation using Orcinol method (Chandrasekaran and Bemiller, 1980, Koch et al., 1991).

vii. Thin layer chromatography (TLC) (de Koster et al., 1994, Rendell et al., 1990).

viii. Gas Chromatography (GC) (Arino et al., 1996, Van Dyke et al., 1993).

ix. High performance liquid chromatography (HPLC) (Deziel et al., 1999, Lepine et al., 2002, Mata-Sandoval et al., 1999).

x. Mass spectrometry (MS) (Deziel et al., 1999).

xi. Fourier transform infrared spectroscopy (Borgund et al., 2007, Gartshore et al., 2000) and Attenuated Total Reflectance (ATR) FTIR (Leitermann et al., 2008).

xii. NMR spectroscopy (Choe et al., 1992, Monteiro et al., 2007).

Combinations of these methods are generally used for the detection and estimation of rhamnolipid production. 


\section{Applications of rhamnolipid biosurfactant}

Compared to chemical surfactants, biological biosurfactant possess numerous attributes that make them invaluable in both environmental and industrial settings (Hommel, 1990, Rahman and Gakpe, 2008, Volkering et al., 1995). Noordman and Janssen (2002) claimed the degradation of hexadecane by rhamnolipid with rates higher as compared to other biosurfactants. Urum et al. (2006), on the other hand compared the effectiveness of biosurfactant rhamnolipid, saponin and sodium dodecyl sulfate (SDS). They found that rhamnolipid and saponin aided crude oil degradation almost equally, whilst SDS was found to be ineffective. Rhamnolipid is therefore the best biosurfactant since it is produced naturally via microbial activity, while SDS is a synthetic surfactant.

Rhamnolipids in particular are biotechnologically important due to their antibacterial, antifungal and antiviral activities (Haferburg et al., 1987, Stanghellini and Miller, 1997, Syldatk et al., 1985). Rhamnolipid biosurfactants increases membrane permeability of the bacterial cells thereby causing cell death. The biosurfactant probably forms molecular aggregates in surface bacterial membranes, leading to the formation of trans-membrane pores (King et al., 1991). Studies conducted by Sotirova et al. (2008) showed the rhamnolipid biosurfactant complex termed PS mediates permeabilizing effects on Gram-positive and Gram-negative bacterial strains, namely B. subtilis and $P$. aeruginosa. They reported that at lower concentrations of rhamnolipid biosurfactant close to CMC, the growth of bacterial cells is not influenced, however concentrations greater than CMC exhibit toxic conditions for B. subtilis cells but not for $P$. aeruginosa as evident from the levels of extracellular proteins. The biosurfactant enhanced levels of extracellular protein in $B$. subtilis cells compared with those of $P$. aeruginosa, which confirmed the higher susceptibility of Gram-positive cells to the effect of the studied biosurfactant. It is evident that the outer membrane of Gram-negative bacteria have lipopolysaccharide (LPS), porin channels, and murein lipoprotein, all of which are absent in Gram-positive bacteria. Also, the outer membrane functions as an efficient permeability barrier that is able to exclude biosurfactant molecules. The permeability barrier property is largely caused by the presence of the LPS layer. Increased cell permeability induced by rhamnolipid biosurfactant was most likely caused by the release of LPS from the outer membrane (Al-Tahhan et al., 2000, Sotirova et al., 2007). Rhamnolipids have been used as emulsifying agents for the transport of drugs to the site of action. Rhamnolipids in combination with the antibiotic, azithromycin facilitated destruction of the bacterial cells by increasing the bacterial membrane permeability (Kohler et al., 2007). P. aeruginosa rhamnolipid mixture was found to inhibit a majority of pathogenic bacteria such as A. faecalis, E. coli, Micrococcus luteus, Mycobacterium phlei, Serratia marcescens and S. epidermidis. The marine bacterium, B. pumilus cell adhesion and biofilm disruption was also achieved using rhamnolipids (unpublished data).

Rhamnolipids also show antifungal activity against Aspergillus niger, Aureobasidium pullulans, Chaetonium globosum and Penicillum crysogenum (Abalos et al., 2001, Rahman and Gakpe, 2008). The zoosporicidal activity of mono and dirhamnolipids against phytopathogens is reported by Stanghellini and Miller (1997). Stanghellini and coworkers (1998) patented their work on rhamnolipid biosurfactants produced by Pseudomonas $s p$. able to rapidly kill zoospores by rupturing the plasma membrane of three representative plant pathogenic microorganisms; namely Pythium aphaniderna- 
tum, Plasmopara lactucae-radicis, and Phytophthora capsici. Rhamnolipid-producing strains also provide control of Pseudoperonospora cubensis, the causal agent of downy mildew of cucurbits, by intercalating into the plasma membrane and thereby destroying the cell structure. Rhamnolipids inhibit the growth of algal species including Heterosigma akashivo and Protocentrum dentatum (Wang et al., 2005). Rhamnolipids also display antiviral properties against pathogens like TMV and potato $\mathrm{X}$ virus (Haferburg et al., 1987). They can be used as adjuvants for vaccines. McClure and Schiller (1992) reported the enhancement of phospholipase C activity after addition of rhamnolipids. Tatjana and Goran (2007) patented their work on rhamnolipids as effective in wound healing, treating burn shock, atherosclerosis, organ transplants, depression, schizophrenia and cosmetics (Tatjana and Goran, 2007). Rhamnolipids are however also responsible for increasing the virulence factors secreted by $P$. aeruginosa that affect the structure of human airway epithelium in the early stages of infection (Zulianello et al., 2006).

In environmental bioremediation, rhamnolipids play a significant role in the treatment of soils contaminated with industrial waste, crude oils, polyaromatic hydrocarbons, refinery products, pesticides and heavy metals (Rahman et al., 2003). The ability of a rhamnolipid mixture produced by $P$. aeruginosa $\mathrm{UG} 2$ to solubilize the pesticides atrazine, trifluralin, and coumaphos was compared with a chemical surfactant Triton $\mathrm{X}-100$. It was observed that the values of maximum micellar solubilization capacities for trifluralin and coumaphos in Triton X-100 were double those for the rhamnolipid mixture, whereas atrazine maximum micellar solubilization capacity value for the rhamnolipid biosurfactant was in the same range as that for the synthetic surfactant (Mata-Sandoval et al., 2000).

Muller-Hurtig et al. (1993) and Finnerty (1994) reviewed the possible use of biosurfactants in soil remediation. Rhamnolipids can alter the physicochemical properties of oil, thereby facilitating the removal of oil from contaminated soils. Rhamnolipids have also shown to enhance the cell surface hydrophobicity of $P$. aeruginosa cells by inducing removal of lipopolysaccharides, thereby increasing the uptake of hydrophobic compounds by the cells (Al-Tahhan et al., 2000). Heavy metals are included on the EPA's list of priority pollutants (Mulligan et al., 2001). Heavy metals pose a persistent problem at many contaminated sites and are being added to soil, water, and air in increasing amounts from a variety of sources including industrial, agricultural and domestic effluents. Heavy metals can be removed from contaminated areas through direct binding of the rhamnolipids to the metals forming a stable complex, which is subsequently removed from the soil (Ochoa-Loza et al., 2001).

In food industries, rhamnolipids serve as a good source of rhamnose sugar that acts as a precursor for high quality flavor components (Linhardt et al., 1989). Van Haesendonck and Vanzeveren (2004) reported the application of rhamnolipid for volume enhancement and for texture modification in bakery and pastry products.

\section{Rhamnolipids and quorum sensing}

QUORUM SENSING MOLECULES IN RHAMNOLIPID PRODUCTION

P. aeruginosa possesses two interrelated QS systems, namely the las and rhl, (Gambello and Iglewski, 1991, Passador et al., 1993, Toder et al., 1991) that regulate different processes including rhamnolipid expression, enzyme production, pyocyanin 
pigment production and maintenance of biofilm architecture (Davies et al., 1998, de Kievit and Iglewsky, 2000, Rumbaugh et al., 2000, Smith and Iglewski, 2003). Production of rhamnolipid is governed by three QS molecules: the twelve carbon Pseudomonas autoinducer 1 (PAI-1) [N-(3-oxododecanoyl) homoserine lactone also known as 3-oxo- $\mathrm{C}_{12}$-HSL] (Pearson et al., 1994), Pseudomonas autoinducer 2 (PAI2) [N-butyryl homoserine lactone known also as $\mathrm{C}_{4}$-HSL] (Pearson et al., 1995), and PQS, [2-heptyl-3-hydroxy-4-quinolone] (Pesci et al., 1999) (Fig. 1).

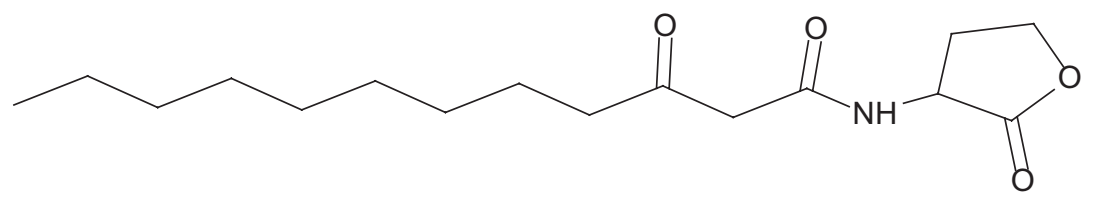

PAl-1 (3-oxo-C12- HSL)

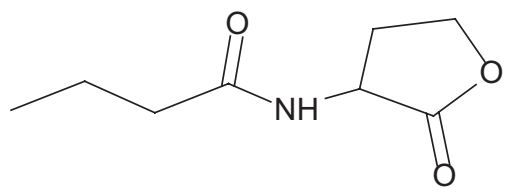

PAI-2 (C4-HSL)

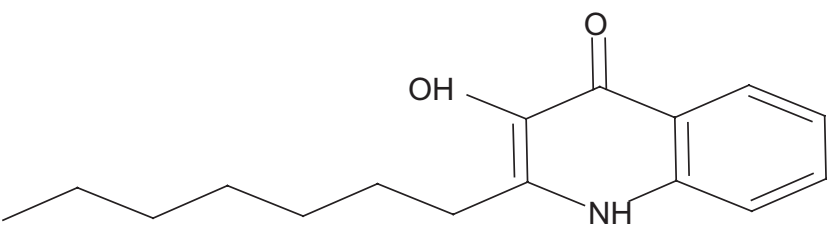

PQS

Figure 1. Quorum sensing molecules in Pseudomonas aeruginosa PAO1. The three quorum sensing molecules denoted as (a) Pseudomonas autoinducer PAI-1 [N-(3-oxododecanoyl) homoserine lactone] also known as 3-oxo- $\mathrm{C}_{12}$-HSL; (b) Pseudomonas autoinducer PAI-2 [N-butyryl homoserine lactone] known as $\mathrm{C}_{4}$-HSL and (c) Pseudomonas Quinolone Signal (PQS), [2-heptyl-3-hydroxy-4-quinolone] coordinates the cellular activities.

\section{Genetic basis of rhamnolipid production}

The production of rhamnolipids is under the control of two quorum sensing systems, namely the las and $r h l \mathrm{QS}$ systems. In P. aeruginosa, the las operon consists of two transcriptional activator proteins, the LasR and LasI, which directs the synthesis of $\mathrm{N}$-3-oxododecanoyl homoserine lactone (PAI-1 or 3-oxo- $\mathrm{C}_{12}$-HSL) autoinducer. Induction of the las $B$ gene that encodes the elastase enzyme and other virulence genes requires the expression of LasR and PAI-1 autoinducer. The production of rhamnolipid is regulated by the $r h l$ system (Johnson and Boese-Marazzo, 1980). The synthesis of rhamnolipids takes place under the coordinated guidance of $\operatorname{rhlAB}$ genes that 
encodes a group of enzymes termed the rhamnosyltransferases (Ochsner et al., 1995). Rhamnolipid is a complex synthesized by two enzymes namely, rhamnosyltransferase 1 and rhamnosyltransferase 2 . The $r h l$ system consists of transcriptional activator proteins RhlR and RhlI, which regulates the synthesis of a QS molecule, N-butyryl homoserine lactone (PAI-2 also called the $\mathrm{C}_{4}$-HSL) (Ochsner et al., 1994b, Pearson et al., 1995). The transcriptional activator RhlR activates the transcription of $\operatorname{rhlAB}$ operon genes, coding for rhamnosyltransferase 1 (Ochsner et al., 1994b), and another gene, $r h l C$ encoding for the rhamnosyltransferase 2 (Rahim et al., 2001). The genes involved in the production of rhamnolipid are mentioned in table 1. With increase in bacterial cell density, the induction of las quorum sensing system takes place resulting in an increase in the concentration of PAI-1 (3-oxo- $\left.\mathrm{C}_{12}-\mathrm{HSL}\right)$ autoinducer molecule. This quorum sensing molecule (PAI-1) then binds to the transcriptional activator site LasR and forms the LasR-PAI-1 complex. The LasR-PAI-1 complexes induces genes controlled by the las quorum-sensing system, including a negative regulator gene rsaL, rhlR (Ochsner et al., 1994b, Pearson et al., 1995) and $p q s H$, required for PQS production (Mashburn and Whiteley, 2005). The activity of these signals is dependent upon their ability to dissolve in and freely diffuse through the aqueous solution.

Table 1. Quorum sensing systems prevalent in P. aeruginosa suggesting the genes and functions assisting rhamnolipid production.

\begin{tabular}{lll}
\hline $\begin{array}{l}\text { Quorum } \\
\text { sensing system }\end{array}$ & $\begin{array}{l}\text { Genes } \\
\text { involved }\end{array}$ & Enzyme product \\
\hline las system & las $\mathrm{I}$ & Autoinducer synthesis, LasI synthase \\
& las $\mathrm{R}$ & Transcriptional regulator, LasR synthase \\
& las $\mathrm{A}$ & LasA protease precursor \\
& las $\mathrm{B}$ & Elastase LasB \\
$r h l$ system & $r h l \mathrm{I}$ & Autoinducer synthesis protein, RhlI synthase \\
& $r h l \mathrm{R}$ & Transcriptional regulator, RhlR synthase \\
& $r h l A B$ & Rhamnosyltransferase 1 \\
& $r h l \mathrm{C}$ & Rhamnosyltransferase 2 \\
& $r h l \mathrm{G}$ & $\beta$-ketoacyl reductase \\
& $p q s \mathrm{~A}$ & coenzymeA ligase \\
& $p q s \mathrm{~B}$ & Homologous to $\beta$-keto acyl carrier protein synthase \\
& $p q s \mathrm{C}$ & Homologous to $\beta$-keto acyl carrier synthase (3-oxoacyl- \\
& & [acyl-carrier protein]) \\
& $p q s \mathrm{D}$ & 3-oxoacyl-[acyl-carrier protein] synthase III \\
& $p q s \mathrm{E}$ & Quinolone signal response protein \\
& $p q s \mathrm{H}$ & Probable FAD-dependent monooxygenase \\
& $p q s \mathrm{~L}$ & Probable FAD-dependent monooxygenase \\
\hline
\end{tabular}

P. aeruginosa produced rhamnolipid biosurfactant that enhances the solubility of PQS in aqueous solutions (Calfee et al., 2005). However unlike other QS, the hydrophobic 
PQS is transported primarily through outer membrane vesicles (Mashburn and Whiteley, 2005), the formation of which are PQS-induced (Mashburn-Warren et al., 2008, Mashburn-Warren et al., 2009). PQS (3, 4-hydroxy-2-heptylquinoline), as mentioned earlier acts as a link between las and $r h l$ quorum sensing systems (MullerHurtig et al., 1993). Using mutants deficient in the synthesis of PQS, the cells of $P$. aeruginosa make less rhamnolipid than the wild type strains (Diggle et al., 2003). PQS here either directly or indirectly induces the rhlI gene which directs the production of PAI-2 $\left(\mathrm{C}_{4}\right.$-HSL) quorum sensing molecule that binds to and activates RhlR (McKnight et al., 2000). The operon, rhlAB that encodes these enzymes responsible for rhamnolipid production is controlled at the transcriptional and translational levels by RhlR and C4-HSL (Ochsner and Reiser, 1995). The RhlR-PAI-2 complex induces genes controlled by the $r h l$ quorum sensing system for the production of rhamnolipid. The las system controls the expression of transcriptional activator RhlR (Fig. 2). Along with this an important gene, $r h l G$ is involved in the synthesis of $\beta$-hydroxyacid moiety of rhamnolipids (Campos-Garcia et al., 1998). A QS hierarchy therefore exists in $P$. aeruginosa las and $r h l$ systems for the synthesis of rhamnolipid.

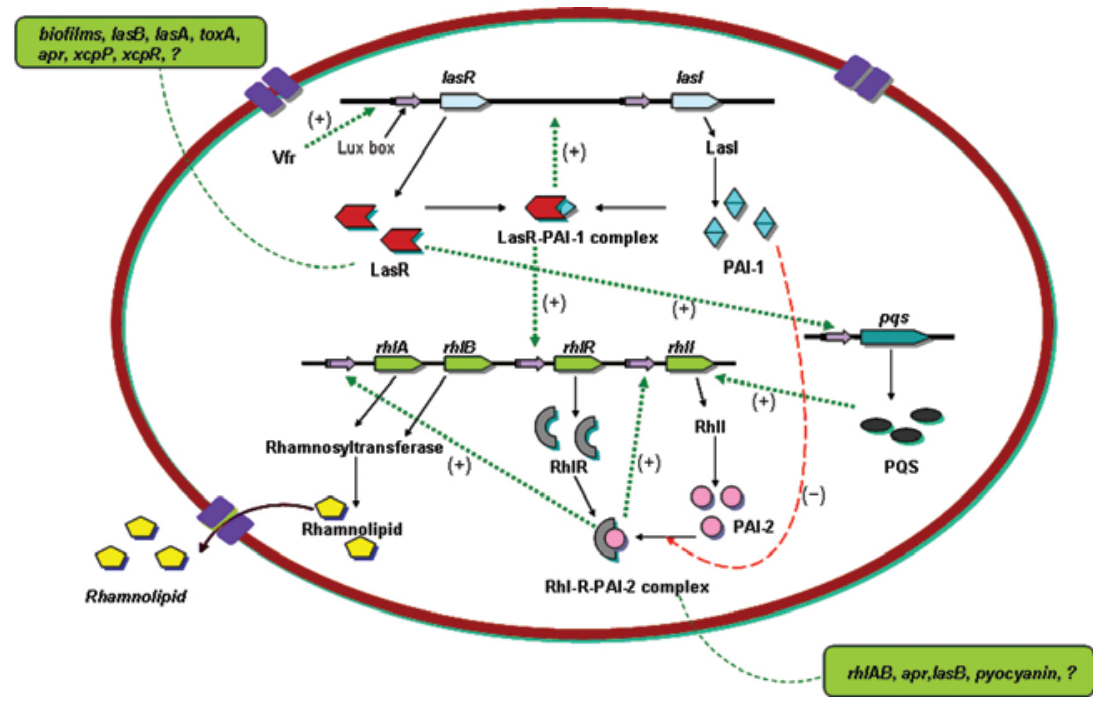

Figure 2. Schematic representation of the las and $r h l$ genes and quorum sensing molecules in Pseudomonas aeruginosa for the production of rhamnolipid. The las system produces transcriptional activators, LasR and LasI (producing PAI-1). The $r h l A$ and $r h l B$ genes are arranged as an operon and are clustered with rhlR and rhlI. These genes, rhlABRI directs the synthesis of rhamnosyltransferase and transcriptional activators, RhlR and RhlI (producing PAI-2), which are responsible for the production of rhamnolipids. Vfr induces las $R$ and the concentration of PAI-1 increases where it binds to and activates LasR (Albus et al., 1997). The autoinducer PAI-1 (encoded by lasI) binds with LasR and forms a LasR-PAI-1 complex. This complex regulates the transcription of $r h l R$. $r h l R$ produces RhlR protein, which binds to the PAI-2 autoinducer resulting in RhlR-PAI-2 complex that interacts with the rhlA promoter (lux box) to begin transcription of the rhamnolipid producing $r h l A B$ gene. Here (+) indicates transcriptional activation and $(-)$ indicates transcriptional repression of the concerned genes.

\section{Biochemical pathway of rhamnolipid production}

Initiation of quorum sensing is contingent upon the accumulation of sufficient signal molecules. Due to this stringency, quorum sensing is only initiated once the population 
reaches a critical threshold (Fuqua et al., 1994, Pierson et al., 1994). In P. aeruginosa, rhamnolipid production initially depends on PAI-1 and PAI-2 diffusible molecules, which interact with the activators, LasR and RhIR at high bacterial cell densities. For more information refer to Fig. 3.

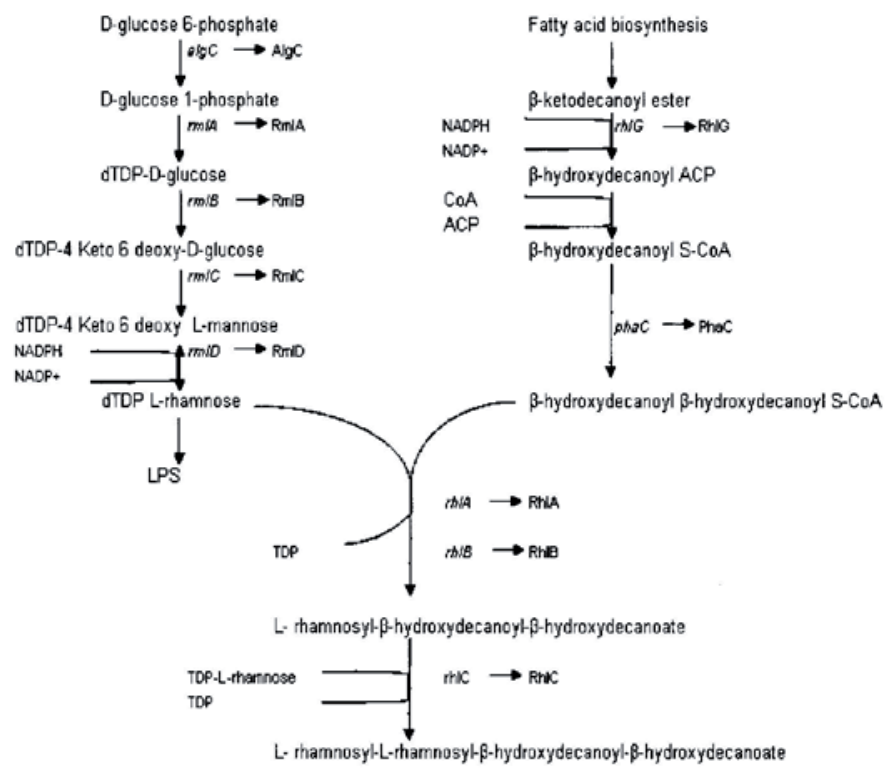

Figure 3. Biochemical pathway for rhamnolipid biosynthesis showing the genes and proteins involved in Pseudomonas aeruginosa PAO1 (Maier and Soberson-Chavez, 2000). The synthesis of rhamnolipid proceeds via the transfer of TDP-L-rhamnose. The 3-(3-hydroxyalkanoyloxy) alcanoic acid (HAA) is synthesized by RhlA enzyme and is then converted to mono-rhamnolipid by RhlB enzyme (Deziel et al., 2003, Ochsner et al., 1994b). The mono-rhamnolipid is converted to di-rhamnolipid by the RhlC enzyme (Rahim et al., 2001). CoA- $\beta$-hydroxyacids are the precursors of rhamnolipids. The $r h l A B$ operon and $r h l C$ genes are induced by homoserine lactone activated RhIR and are thus under the control of QS system (Ochsner et al., 1994b, Rahim et al., 2001). RhIR protein is known to activate $r h l G$ transcription for rhamnolipid production. The biochemical synthesis of rhamnolipid is shown in fig. 3. Many QS molecules are known to regulate the synthesis of rhamnolipids. An autoinducer, Nbutyryl homoserine lactone (PAI-2) present in P. aeruginosa restores rhamnolipid production in P. aeruginosa rhlI mutant (Pearson et al., 1995, Winson et al., 1995). PAI-2 and RhlR enhances the expression of rhll in E. coli (Latifi et al., 1996). These finding suggests the importance of $r h l R$ and $r h l l$ quorum sensing components required for the auto-induction of rhamnolipid biosynthesis genes $r h l A$ and $r h l B$ (Pearson et al., 1997). The activator LasR-PAI1 complex induces the production of several virulence factors, such as the alkaline protease, exotoxin A and also regulates the expression of secretion proteins (Gambello et al., 1993, Morihara and Homma, 1985, Toder et al., 1991, 1994). The Rhl-PAI2 complex present in the biosynthesis of rhamnolipid induces expression of the LasA and LasB proteases as well as the secretion proteins (Xcp). In addition, the complex also controls expression of $r h l A B$ and $r h l G$ genes responsible for rhamnosyltransferase (Burger et al., 1963) and synthesis of hydroxyalkanoate for rhamnolipid production respectively (Campos-Garcia et al., 1998).

\section{Enhancement of rhamnolipid production}

P. aeruginosa is an opportunistic pathogen associated with cystic fibrosis and infections associated with severe burns. This bacterium is known for its resistance towards a variety of antibiotics and is one of the leading causes of nosocomial infections (Tummler et al., 1991). Numerous studies on P. aeruginosa and rhamnolipid 
biosynthesis have improved the understanding of methods for the enhancement of rhamnolipid production.

\section{NUTRITIONAL AND ENVIRONMENTAL CONDITIONS}

In $P$. aeruginosa, rhamnolipid production occurs typically in late exponential or stationary phase (Guerra-Santos et al., 1986). The presence of nutrients, such as carbon and nitrogen, also play an important role in the production of rhamnolipids (Wu et al., 2008). P. aeruginosa growth and rhamnolipid production can occur using a range of different primary carbon sources. The highest level of rhamnolipid production in $P$. aeruginosa occurs when using vegetable based oils as carbon sources including soybean oil (Lang and Wullbrandt, 1999), corn oil (Linhardt et al., 1989), canola oil (Sim et al., 1997), and olive oil (Robert et al., 1989). Rhamnolipid production is dependent upon environmental and nutritional conditions. Environmental factors play a crucial role in influencing the productivity and efficacy of rhamnolipids. In general, as a biosurfactant, rhamnolipid activity is controlled by environmental conditions such as pH, salinity and temperature (Ilori et al., 2005, Inakollu et al., 2004, Jirasripongpun, 2002). Ilori et al (2005) pointed out that the chemical structure of biosurfactant gives benefit for hydrocarbon degradation and very unlikely to be disrupted due to extreme temperature and pH. Benka-Coker and Ekundayo (1996) highlighted the amount of oil might affect the biodegradation rate as well, due to poor aeration and lack of oxygen. The action of Pseudomonas in degrading oil is accelerated by the formation of rhamnolipid. The size and structure of hydrocarbon substrates may however slow down this oil degradation process.

\section{SUPPLEMENTING EXOGENOUS QS MOLECULES}

In mutants, unable to produce rhamnolipids, external addition of autoinducer molecules, $\mathrm{N}$-acyl homoserine lactones regains the phenotype of rhamnolipid production. Kuniho et al (1998) found that autoinducer activity increased approximately tenfold in fed batch system which strongly correlated with increased rhamnolipid production. Enhancement of rhamnolipid production occurred in the presence of either N-(3-oxohexanoyl)-L-homoserine lactone (OhDHL) or N-(3-oxododecanoyl)L-homoserine lactone (OdDHL). Overall, the presence of exogenous autoinducer increased rhamnolipid production five-fold, with maximal yields occurring during stationary phase of growth. Construction of rhamnolipid mutants has allowed for the identification of several genes that are essential for rhamnolipid biosynthesis. The first, identified in $P$. aeruginosa, comprises the $r h l A B$ operon; here both the genes play an essential role in rhamnolipid production (Ochsner et al., 1994a). The rhlAB genes encode rhamnosyltransferase I complex involved in the formation of the RhlAB heterodimer (Ochsner et al., 1994b) and defects in either gene result in deficiencies in rhamnolipid production (Deziel et al., 2003). In addition to the two aforementioned genes, rhlC (encoding rhamnosyltransferase II, which adds the second rhamnosyl group to form RL2) is essential for the production of RL2, but is not essential for RL1 production (Rahim et al., 2001). A stable mutant strain would be a great advantage for rhamnolipid production by fermentation (Wang et al., 2007). 


\section{GENETIC ENGINEERING}

Screening high rhamnolipid-producing microorganism from the natural environment is a good strategy; however engineering strains for rhamnolipid production is another alternative. Rhamnolipid production could also be effectively enhanced by cloning the wild-type rhlI gene into a suitable strain such as $E$. coli, or by the addition of $P$. aeruginosa cell-free spent supernatant containing the autoinducer molecules (Ochsner and Reiser, 1995). Rhamnolipid production has been shown to be transcriptionally regulated by quorum-sensing circuitry (Ochsner and Reiser, 1995, Heurlier et al., 2004). In a recent study, Cha et al (2008) were able to successfully increase rhamnolipid production by cloning both the $\operatorname{rhl} A B$ rhamnosyltransferase genes and the rhlRI quorum sensing system into $P$. putida to enhance rhamnolipid production.

In another study carried out by Wang and co-workers (2007) the novel transposome biotechnique was used. They integrated successfully the key genes of rhamnolipid biosynthesis into the chromosome of $P$. aeruginosa and $E$. coli cells, which were originally devoid of rhamnolipid production and the engineered strains, thus produced rhamnolipid. This technique would allow one to create a stable insertion mutation in a wide range of bacteria (Hoffman et al., 2000). Unlike plasmid-based engineered strain, transposon-based strains could exist stably under no drug-selection pressure, and the integration site of the targeted gene(s) would easily be confirmed by inversePCR, DNA sequencing, and alignment with a vast repository of genome information available from public database. The mechanism of gene regulation enables controlled production of rhamnolipid. Ochsner et al (1994b) reported that $r h l \mathrm{R}$ gene is essential in synthesizing rhamnolipids since the interruption at this locus contributed to the formation of rhamnolipid deficient mutants.

By using a suitable medium with the addition of QS molecules (AHL) at an early stage of bacterial growth along with genetically modified bacterial strains could be used for enhanced synthesis of rhamnolipid. A recent development in synthetic biology where synthetic molecules of quorum sensing are used for induction has shown numerous applications. Better understanding of the QS based synthetic networks is useful and has been applied in studies related to programming cell death in E. coli (Balagadde et al., 2005), constructing microbial consortia (Brenner et al., 2007), building of artificial intercellular communication and quorum-sensing behavior in prokaryotes (Bulter et al., 2004) and eukaryotes (Chen and Weiss, 2005). The topic is of significant interest and there is a need to explore it in great detail.

\section{Conclusion}

Rhamnolipids are effective biosurfactants with numerous applications. The production of rhamnolipids is under the control of quorum sensing. Over the past decade, significant strides have been made towards understanding the cell to cell communication, especially in the production of rhamnolipids biosurfactant. Evidence suggests that knowledge of cell to cell communication molecules and their role in biosurfactant production could be exploited to industrial scale production. There are numerous methods of enhancing rhamnolipids, however knowledge of the genes required for biosurfactant production can be critical for application in industry. 
Currently, biosurfactants are unable to compete economically with chemically synthesized compounds in the market due to high production costs. Once the genes required for biosurfactant production have been identified, they can be placed under the regulation of strong promoters in nonpathogenic, heterologous hosts to enhance production. The production of rhamnolipids could be increased by cloning both the $\operatorname{rhlAB}$ rhamnosyltransferase genes and the rhlRI quorum sensing system into a suitable bacterium such as E. coli or $P$. putida and facilitate rhamnolipid production. Biosurfactants can also be genetically engineered for different industrial applications assuming there is a strong understanding of both the genetics and the structure-function relationships of each component of the molecule. Genetic engineering of surfactin has already been reported, with recent papers describing the creation of novel peptide structures from the genetic recombination of several peptide synthetases. Recent application of dynamic metabolic engineering strategies for controlled gene expression could lower the cost of fermentation processes by increasing the product formation. Therefore, by integrating a genetic circuit into applications of metabolic engineering the biochemical production can be optimized. Furthermore, novel strategies could be designed on the basis of information obtained from the studies of quorum sensing and biosurfactants produced suggesting enormous practical applications.

\section{Acknowledgements}

DHD would like to acknowledge Bhabha Atomic Research Centre (BARC) and University of Pune (UoP) collaborative research programme. PKSMR wishes to thank UK- Bioscience for Business KTN for the award of FROPTOP fund to explore the biocatalytic study of biosurfactant production from renewable resources. RJCM is funded by the Norman Hackerman Advanced Research Program of the Texas Higher Education Coordinating Board (003615-0037-2007).

\section{References}

Abalos, A., Pinazo, A., Infante, M.R., Casals, M., Garcia, F. et al. (2001) Physicochemical and antimicrobial properties of new rhamnolipids produced by Pseudomonas aeruginosa AT10 from soybean oil refinery wastes. Langmuir 17, 1367-1371

Albus, A.M., Pesci, E.C., Runyen-Janecky, L.J., West, S.E.H. And Iglewski, B.H. (1997) Vfr controls quorum sensing in Pseudomonas aeruginosa. Journal of Bacteriology 179, 3928-3935

Al-tahHan, R.A., SAndrin, T.R., Bodour, A.A. And Maier, R.M. (2000) Rhamnolipidinduced removal of lipopolysaccharide from Pseudomonas aeruginosa: effect on cell surface properties and interaction with hydrophobic substrates. Applied and Environmental Microbiology 66, 3262-3268

Arino, S., Marchal, R. and Vandecasteele, J.P. (1996) Identification and production of a rhamnolipidic biosurfactant by a Pseudomonas species. Applied Microbiology and Biotechnology 45, 162-168

Balagadde, F.K., You, L., Hansen, C.L., Arnold, F.H. and Quake, S.R. (2005) Longterm monitoring of bacteria undergoing programmed population control in a 
microchemostat. Science 309, 137-140

Balagadde, F.K., Song, H., Ozaki, J., Collins, C.H., Barnet, M. et al. (2008) A synthetic Escherichia coli predator-prey ecosystem. Molecular and Systematic Biology 4, 1-8

Bassler, B.L., Greenberg, E.P. And Stevens, A.M. (1997) Cross-species induction of luminescence in the quorum-sensing bacterium Vibrio harveyi. Journal of Bacteriology 179, 4043-4045

Basu, S., Gerchman, Y., Collins, C.H., Arnold, F.H. And Weiss, R. (2005) A synthetic multicellular system for programmed pattern formation. Nature 434, 1130-1134

Bejerano-sagie, M. AND XAVIER, K.B. (2007) The role of small RNAs in quorum-sensing. Current Opinion in Microbiology 10, 189-98

BENKA-COKER, M.O. AND EKUNDAYA, J.A. (1996) Applicability of evaluating the ability of microbes isolated from an oil spill site to degrade oil. Environment Monitor Assessment 45, 259-272

Buarnsholt, T., Jensen, P.O., Burmolle, M., Hentzer, M., Haagensen, J.A.J et al. (2005) Pseudomonas aeruginosa tolerance to tobramycin, hydrogen peroxide and polymorphonuclear leukocytes is quorum-sensing dependent. Microbiology $\mathbf{1 5 1}$, 373-383

Boles, B.R., Thoendel, M. AND Singh, P.K. (2005) Rhamnolipids mediate detachment of Pseudomonas aeruginosa from biofilms. Molecular Microbiology 57, 1210-1223

Borgund, A.E., ERSTAD, K. AND BARTH, T. (2007) Normal phase high performance liquid chromatography for fractionation of organic acid mixtures extracted from crude oils. Journal of Chromatography: A 1149, 189-196.

Brenner, K., Karig, D.K., Weiss, R. And ARnold, F.H. (2007) Engineered bidirectional communication mediates a consensus in a microbial biofilm consortium. Proceedings of the National Academy of Sciences (USA) 104, 17300-17304

Bulter, T., Lee, S.G., Wong, W.W., Fung, E., Conner, M.R. et al. (2004) Design of artificial cell-cell communication using gene and metabolic networks. Proceedings of the National Academy of Sciences (USA) 101, 2299-2304

Burger, M.M., Glaser, L. And Burton, R.M. (1963) The enzymatic synthesis of a rhamnose-containing glycolipid by extracts of Pseudomonas aeruginosa. Journal of Biological Chemistry 238, 2595-2602

Calfee, M.W., Shelton, J.G., Mccubrey, J.A. And Pesci, E.C. (2005) Solubility and bioactivity of the Pseudomonas quinolone signal are increased by a Pseudomonas aeruginosa-produced surfactant. Infection Immunity 73, 878-882

Camara, M., Williams, P. and Hardman, A. (2002) Controlling infection by tuning in and turning down the volume of bacterial small-talk. Lancet 2, 667-676

Campos-garcia, A., Jesu, S., Caro, A.D., Jera, R., Miller-maier, R.M. et al. (1998) The Pseudomonas aeruginosa rhlG gene encodes an NADPH dependent $\beta$-ketoacyl reductase which is specifically involved in rhamnolipid synthesis. Journal of Bacteriology 180, 4442-4451

Cao, H., Krishnan, G., Goumnerov, B., Tsongalis, J., Tompkins, R. et al. (2001) A quorum sensing-associated virulence gene of Pseudomonas aeruginosa encodes a LysR-like transcription regulator with a unique self regulatory mechanism. Proceedings of the National Academy of Sciences (USA) 98, 14613-14618

Cha, M., LeE, N., KIM, M., KIM, M. AND LEE, S. (2008) Heterologous production of Pseudomonas aeruginosa EMS1 biosurfactant in Pseudomonas putida. Bioresource 
Technology 99, 2192-2199

Chandrasekaran, E.V. and Bemiller, J.N. (1980) Constituent analysis of glycosaminoglycans. In Methods in Carbohydrate Chemistry. Eds. R. L. Whistler and M. L. Wolform, pp 89-96. Academic Press, New York

Chen, X., Schauder, S., Potier, N., Van dorsselaer, A., Pelczer, I. et al. (2002) Structural identification of a bacterial quorum-sensing signal containing boron. Nature 415, 545-549

Chen, M.T. And Weiss, R. (2005) Artificial cell-cell communication in yeast Saccharomyces cerevisiae using signaling elements from Arabidopsis thaliana. Nature Biotechnology 23, 1551-1555

Choe, B.Y., Krishna, N.R. And Pritchard, D.G. (1992) Proton NMR study on rhamnolipids produced by Pseudomonas aeruginosa. Magnetic Resonance Chemistry 30, 1025-1026

Costerton, J.W., Cheng, K.J., Geesey, G.G., Ladd, T.I., Nickel, J.C. et al. (1987) Bacterial biofilms in nature and disease. Annual Reviews of Microbiology 41, 435464

Davey, M.E. AND O'Toole, G.A. (2000) Microbial biofilms: from ecology to molecular genetics. Microbiology and Molecular Biology Reviews 64, 847-867

Davey, M.E., Caiazza, N.C. And O'toole, G.A. (2003) Rhamnolipid surfactant production affects biofilm architecture in Pseudomonas aeruginosa PAO1. Journal of Bacteriology 185, 1027-1036

Davies, D.G., Parsek, M.R., Pearson, J.P., Iglewski, B.H., Costerton, J.W. et al. (1998) The involvement of cell-cell signals in the development of a bacterial biofilm. Science 280, 295-298

De KIEvit, T.R. AND IGLewsky, B.H. (2000) Bacterial quorum sensing in pathogenic relationships. Journal of Bacteriology 68, 4839-4849

De koster, C.G., Vos, B., Versluis, C., Heerma, W. and Haverkamp, J. (1994) High-performance TLC/fast atom bombardment (tandem) mass spectrometry of Pseudomonas rhamnolipids. Biological Mass Spectroscopy 23, 179-185

Desai, J.D. AND BANAT, I.M. (1997) Microbial production of surfactants and their commercial potential, Microbiology and Molecular Biology Reviews 61, 47-64

Deziel, E., Lepine, F., Dennie, D., Boismenu, D., Mamer, O.A. et al. (1999) Liquid chromatography/mass spectrometry analysis of mixtures of rhamnolipids produced by Pseudomonas aeruginosa strain 57RP grown on mannitol or naphthalene. Biochimica Biophysica Acta 1440, 244-252

Deziel, E., Lepine, F., Milot, S. And Villemur, R. (2000) Mass spectrometry monitoring of rhamnolipids from a growing culture of Pseudomonas aeruginosa strain 57RP. Biochimica Biophysica Acta 1485, 145-152

Deziel, E., Lepine, F., Milot, S. And Villemur, R. (2003) rhlA is required for the production of a novel biosurfactant promoting swarming motility in Pseudomonas aeruginosa: 3-(3- hydroxyalkanoyloxy) alkanoic acids (HAAs), the precursors of rhamnolipids. Microbiology 149, 2005-2013

Deziel, E., Lepine, F., Milot, S., He, J., Mindrinos, M.N. et al. (2004) Analysis of Pseudomonas aeruginosa 4-hydroxy-2-alkylquinolines (HAQs) reveals a role for 4-hydroxy-2-heptylquinoline in cell-to-cell communication. Proceedings of the National Academy of Sciences (USA) 101, 1339-1344

Diggle, S.P., Winzer, K., ChHabra, S.R., Worrall, K.E., Camara, M. et al. (2003) The 
Pseudomonas aeruginosa quinolone signal molecule overcomes the cell densitydependency of the quorum sensing hierarchy, regulates $r h l$-dependent genes at the onset of stationary phase and can be produced in the absence of LasR. Molecular Microbiology 50, 29-43

Duan, K., Dammel, C., Stein, J., Rabin, H. and Surette, M.G. (2003) Modulation of Pseudomonas aeruginosa gene expression by host microflora through interspecies communication. Molecular Microbiology 50, 1477-1491

Engebrecht, J., Nealson, K. And Silverman, M. (1983) Bacterial bioluminescence: isolation and genetic analysis of functions from Vibrio fischeri. Cell 32, 773-781

FINNERTY, W.R. (1994) Biosurfactants in environmental biotechnology. Current Opinion in Biotechnology 5, 291-295

Fuqua, W.C., Winans, S.C. And GreenberG, E.P. (1994) Quorum sensing in bacteria: the LuxR-LuxI family of cell density-responsive transcriptional regulators. Journal of Bacteriology 176, 269-275

FuQUA, C. AND GREENBERG, E.P. (2002) Listening in on bacteria: acyl-homoserine lactone signalling. Nature Reviews in Molecular and Cell Biology 3, 685-695

Gallagher, L.A., Mcknight, S.L., Kuznetsova, M.S., Pesci, E.C. and Manoil, C. (2002) Functions required for extracellular quinolone signaling by Pseudomonas aeruginosa. Journal of Bacteriology 184, 6472-6480

Gambello, M.J. and Iglewski, B.H. (1991) Cloning and characterization of the Pseudomonas aeruginosa las $R$ gene, a transcriptional activator of elastase expression. Journal of Bacteriology 173, 3000-3009

Gambello, M.J., KaYe, S. And IGLEwski, B.H. (1993) LasR of Pseudomonas aeruginosa is a transcriptional activator of the alkaline protease gene (apr) and an enhancer of exotoxin A expression. Infection and Immunity 61, 1180-1184

GARTSHORE, J., Lim, Y.C. AND COOPER, D.G. (2000) Quantitative analysis of biosurfactants using Fourier Transform Infrared (FT-IR) spectroscopy. Biotechnology Letters 22 , 169-172

Gilson, L., KuO, A. And Dunlap, P.V. (1995) AinS and a new family of autoinducer synthesis proteins. Journal of Bacteriology 177, 6946-6951

Givskov, M., De nys, R., Manefield, M., Gram, L., Maximilien, R. et al. (1996) Eukaryotic intereference with homoserine lactone mediated prokaryotic signalling. Journal of Bacteriology 178, 6618-6622

Guerra-santos, L., Kappeli, O. And Fiechter, A. (1984) Pseudomonas aeruginosa biosurfactant production in continuous culture with glucose as carbon source. Applied and Environmental Microbiology 48, 301-305

Guerra-santos, L., Kappeli, O. And Fiechter, A. (1986) Dependence of Pseudomonas aeruginosa continuous culture biosurfactants production on nutritional and environmental factors. Applied Microbiology and Biotechnology 24, 443-448

Gunther, N.W. IV., Nunez, A., Fett, W. and Solaiman, D.K. (2005) Production of rhamnolipids by Pseudomonas chlororaphis, a nonpathogenic bacterium. Applied Environmental Microbiology 71, 2288-2293

Haferburg, D., Hommel, R., Kleber, H.P., Kluge, S., Schuster, G. et al. (1987) Antiphytoviral activity of a rhamnolipid from Pseudomonas aeruginosa. Acta Biotechnology 7, 353-356

Haussler, S., Nimtz, M., Domke, T., Wray, V. and Steinmetz, I. (1998) Purification and characterization of a cytotoxic exolipid of Burkholderia pseudomallei. Infection and 
Immunity 66, 1588-1593

Haussler, S., Ziegler, I., Lottel, A., Von gotz, F., Rohde, M. et al. (2003) Highly adherent small-colony variants of Pseudomonas aeruginosa in cystic fibrosis lung infection. Journal of Medical Microbiology 52, 295-301

HELBERT, J.R. AND BROWN, K.D. (1957) Color reaction of anthrone with monosaccharide mixtures and oligo- and polysaccharides containing hexuronic acids. Analytical Chemistry 29, 1464-1466

Hentzer, M., Teitzel, G.M., Balzer, G.J., Heydorn, A., Molin, S. et al. (2001) Alginate over-production affects Pseudomonas aeruginosa biofilm structure and function. Journal of Bacteriology 183, 5395-5401

Herman, D.C., Zhang, Y. AND Miller, R.M. (1997) Rhamnolipid (biosurfactant) effects on cell aggregation and biodegradation of residual hexadecane under saturated flow conditions. Applied and Environmental Microbiology 63, 3622-3627

Heurlier, K., Williams, F., Heeb, S., Dormond, C., Pessi, G. et al. (2004) Positive control of swarming, rhamnolipid synthesis, and lipase production by the posttranscriptional RsmA/RsmZ system in Pseudomonas aeruginosa PAO1. Journal of Bacteriology 186, 2936-2945

Heyd, M., Kohnert, A., Tan, T.H., Nusser, M., Kirschhofer, F. et al. (2008) Development and trends of biosurfactant analysis and purification using rhamnolipids as an example. Analytical and Bioanalytical Chemistry 391, 1579-1590

Hoffman, L.M., JendrisaK, J.J., Meis, R.J., Goryshin, I.Y. and Reznikof, S.W. (2000) Transposome insertional mutagenesis and direct sequencing of microbial genomes. Genetica 108, 19-24

Holden, P.A., Lamontagne, M.G., Bruce, A.K., Miller, W.G. And Lindow, S.E. (2002) Assessing the role of Pseudomonas aeruginosa surface-active gene expression in hexadecane biodegradation in sand. Applied and Environmental Microbiology 68 , 2509-2518

Hommel, R. (1990) Formation and physiological role of biosurfactants produced by hydrocarbon utilizing microorganisms. Biodegradation 1, 107-119

Ilori, M.O., Amobi, C.J. AND Odocha, A.C. (2005) Factors affecting the production of oil degrading Aeromonas sp. isolated from a typical environment. Chemosphere 61, 985-992

Inakollu, S., Hung, H.C. And Shreve, G.S. (2004). Biosurfactant enhancement of microbial degradation of various structural classes of hydrocarbon in mixed water systems. Environmental Engineering Science 21, 463-469

Inoue, T., Shingaki, R. And Fukui, K. (2008) Inhibition of swarming motility of Pseudomonas aeruginosa by branched-chain fatty acids. FEMS Microbiology Letters 281, 81-86

Irie, Y., O’toole, G. AND Yuk, M.H. (2005) Pseudomonas aeruginosa rhamnolipids disperse Bordetella bronchiseptica biofilms. FEMS Microbiology Letters 250, 237-243

JARvis, F.G. AND Johnson, M.J.A. (1949) Glycolipid produced by Pseudomonas aeruginosa. Journal of Americal Chemical Society 71, 4124-4126

Jensen, P.O., Buarnsholt, T., Phipps, R., Rasmussen, T.B., Calum, H. et al. (2007) Rapid necrotic killing of polymorphonuclear leukocytes is caused by quorum-sensingcontrolled production of rhamnolipid by Pseudomonas aeruginosa. Microbiology 153, 1329-1338 
JIRASRIPONGPUN, K. (2002) The characterization of oil-degrading microorganisms from lubricating oil contaminated (scale) soil. Letters in Applied Microbiology 35, 296-300

Johnson, M.K. And Boese-Marazzo, O. (1980) Production and properties of heat-stable extracellular hemolysin from Pseudomonas aeruginosa. Infection and Immunity 29, 1028-1033

King, A.T., Davey, M.R., Mellor, I.R., Mulligan, B.J. And Lowe, K.C. (1991) Surfactant effects on yeast cells. Enzyme and Microbial Technology 13, 148-153

Kleerebezem, M., Quadri, L.E.N., KuiPers, O.P. And Devos, W.M. (1997) Quorum sensing by peptide pheromones and two component signal transduction systems in Gram positive bacteria. Molecular Microbiology 24, 895-904

Koch, A.K., Kappeli, O., Fiechter, A. AND Reiser, K. (1991) Hydrocarbon assimilation and biosurfactant production in Pseudomonas aeruginosa mutants. Journal of Bacteriology 173, 4212-4219

Kohler, T., Curty, L.K., Barja, F., Van delden, C. And Pechere, J.C. (2000) Swarming of Pseudomonas aeruginosa is dependent on cell-to-cell signaling and requires flagella and pili. Journal of Bacteriology 182, 5990-5996

Kohler, T., Dumas, J.L. And VAn DELDEn, C. (2007) Ribosome protection prevents azithromycin-mediated quorum sensing modulation and stationary phase killing of Pseudomonas aeruginosa. Antimicrobial Agents Chemotherapy 51, 4243-4248

Kownatzki, R., Tummler, B. And Doring, G. (1987) Rhamnolipid of Pseudomonas aeruginosa in sputum of cystic fibrosis patients. Lancet 1, 1026-1027

Kuniho, N., Yoshimot, A. And YamadA, Y. (1998) Correlation between autoinducers and rhamnolipids production by Pseudomonas aeruginosa IFO 3924. Journal of Fermentation Bioengineering 86, 608-610

LANG, S. AND Wullbrandt, D. (1999) Rhamnose lipids-biosynthesis, microbial production and application potential. Applied Microbiology and Biotechnology 51, 22-32

Latifi, A., Foglino, M., Tanaka, K., Williams, P. And LaZdunski, A. (1996) A hierarchical quorum-sensing cascade in Pseudomonas aeruginosa links the transcriptional activators LasR and RhIR (VsmR) to expression of the stationary-phase sigma factor RpoS. Molecular Microbiology 21, 1137-1146

Lazdunski, A.M., Ventre, I. And Sturgis, J.N. (2004) Regulatory circuits and communication in gram-negative bacteria. Nature Reviews in Microbiology 2, 581592

Leitermann, F., Syldatk, C. and Hausmann, R. (2008) Fast quantitative determination of microbial rhamnolipids from cultivation broths by ATR-FTIR Spectroscopy. Journal of Biological Engineering 2, 13 doi:10.1186/1754-1611-2-13

LePine, F., DeZiel, E., Milot, S. And Villemur, R. (2002) Liquid chromatographic/mass spectrometric detection of the 3-(3-hydroxyalkanoyloxy)alkanoic acid precursors of rhamnolipids in Pseudomonas aeruginosa cultures. Journal of Mass Spectrometry 37, 41-46

Linhardt, R.J., Bakhit, R., Daniels, L., Mayerl, F. and Pickenhagen, W. (1989) Microbially produced rhamnolipid as a source of rhamnose. Biotechnology and Bioengineering 33, 365-368

Lubelski, J., Rink, R., Khusainov, R., Moll, G.N. and KuiPers, O.P. (2008) Biosynthesis, immunity, regulation, mode of action and engineering of the model lantibiotic nisin. 
Cell and Molecular Life Sciences 65, 455-476

Maier, R.M. And Soberon-Chavez, G. (2000) Pseudomonas aeruginosa rhamnolipids: biosynthesis and potential applications. Applied Microbiology and Biotechnology 54, 625-633

Mashburn, L.M. And Whiteley, M. (2005) Membrane vesicles traffic signals and facilitate group activities in a prokaryote. Nature 437, 422-425

Mashburn-warren, L., Howe, J., Garidel, P., Richter, W., Steiniger, F. et al. (2008) Interaction of quorum signals with outer membrane lipids: insights into prokaryotic membrane vesicle formation. Molecular Microbiology 69, 491-502

Mashburn-warren, L., Howe, J., Brandenburg, K. And Whiteley, M. (2009) Structural requirement of the Pseudomonas quinolone signal for membrane vesicle stimulation. Journal of Bacteriology 191, 3411-3414

Masse, E., Majdalani, N. And Gottesman, S. (2003) Regulatory roles for small RNAs in bacteria. Current Opinion in Microbiology 6, 120-124

Mata-sandoval, J.C., Karns, J. And Torrents, A. (1999) HPLC method for the characterization of rhamnolipid mixtures produced by $P$. aeruginosa $\mathrm{UG} 2$ on corn oil. Journal of Chromatography A 864, 211-220

MATA-SANDOVAL, J.C., KARns, J. AND TORRENTS, A. (2000) Effect of rhamnolipids produced by Pseudomonas aeruginosa UG2 on the solubilization of pesticides. Environmental Science and Technology 34, 4923-4930

Mcclure, C.D. AND Schiller, N.L. (1992) Effects of Pseudomonas aeruginosa rhamnolipids on human monocyte derived macrophages. Journal of Leukocyte Biology 51, 97-102

Mcknight, S.L., Iglewski, B.H. And Pesci, E.C. (2000) The Pseudomonas quinolone signal regulates rhl quorum sensing in Pseudomonas aeruginosa. Journal of Bacteriology 182, 2702-2708

Mclean, R.J.C., Whiteley, M., Stickler, D.J. and Fuqua, W.C. (1997) Evidence of autoinducer activity in naturally occurring biofilms. FEMS Microbiology Letters 154, 259-263

Miller, M.B. ANd Bassler, B.L. (2001) Quorum sensing in bacteria. Annual Reviews of Microbiology 55, 165-199

Monteiro, S.A., Sassaki, G.L., De souza, L.M., Meira, J.A., De araujo, J.M. et al. (2007) Molecular and structural characterization of the biosurfactant produced by Pseudomonas aeruginosa DAUPE 614. Chemical and Physical Lipids 147, 1-13

Morihara, K. And Homma, J.Y. (1985) Pseudomonas protease. In Bacterial Enzymes and Virulence eds. I.A. Holder, pp 41-79. Boca Raton, FL, CRC Press.

Muller-hurtig, R., BlaszczyK, R., Wagner, F. And Kosaric, N. (1993) Biosurfactants for environmental control. In Biosurfactant eds. N. Kosaric, pp 447-469. New York, Marcel Dekker Inc.

Mulligan, C.N., Yong, R.N. And Gibbs, B.F. (2001) Heavy metal removal from sediments by biosurfactants. Journal of Hazardous Materials 85, 111-125

Mulligan, C.N. (2005) Environmental applications for biosurfactants. Environmental Pollution 133, 183-198

Nealson, K.H., Platt, T. and Hastings, J.W. (1970) Cellular control of the synthesis and activity of the bacterial luminescent system. Journal of Bacteriology 104, 313-322

Nealson, K.H. and Hastings, J.W. (1979) Bacterial bioluminescence: its control and 
ecological significance. Microbiology Reviews 43, 496-518

Noordman, W.H. And Janssen, D.B. (2002) Rhamnolipid stimulates uptake of hydrophobic compounds by Pseudomonas aeruginosa. Applied and Environmental Microbiology 68, 4502-4508

OchoA-LOZA, F.J., Artiola, J.F. And Maier, R.M. (2001) Stability constants for the complexation of various metals with a rhamnolipid biosurfactant. Journal of Environmental Quality 30, 479-485

Ochsner, U.A., Fiechter, A. And Reiser, J. (1994) Isolation, characterization, and expression in Escherichia coli of the Pseudomonas aeruginosa rhlAB genes encoding a rhamnosyltransferase involved in rhamnolipid biosurfactant synthesis. Journal of Biological Chemistry 269, 19787-19795

Ochsner, U.A., Koch, A.K., Fiechter, A. And Reiser, J. (1994) Isolation and characterization of a regulatory gene affecting rhamnolipid biosurfactant synthesis in Pseudomonas aeruginosa. Journal of Bacteriology 176, 2044-2054

OCHSNER, U.A. AND REISER, J. (1995) Autoinducer-mediated regulation of rhamnolipid biosurfactant synthesis in Pseudomonas aeruginosa. Proceedings of the National Academy of Sciences (USA) 92, 6424-6428

Ochsner, U., Reiser, J., Fiechter, A. AND Witholt, B. (1995) Production of Pseudomonas aeruginosa rhamnolipid biosurfactants in heterologous hosts. Applied and Environmental Microbiology 61, 3503-3506

O'toole, G.A. And Kolter, R. (1998) Flagellar and twitching motility are necessary for Pseudomonas aeruginosa biofilm development. Molecular Microbiology 30, 295-304

PAMP, S.J. ANd TolKeR-NIELSEN, T. (2007) Multiple roles of biosurfactants in structural biofilm development by Pseudomonas aeruginosa. Journal of Bacteriology $\mathbf{1 8 9}$, 2531-2539

Pappas, K., Weingart, C.L. And Winans, S.C. (2004) Chemical communication in proteobacteria: biochemical and structural studies of signal synthases and receptors required for intercellular signaling. Molecular Microbiology 53, 755-769

PARSEK, M.R. AND GREenberG, E.P. (2000) Acyl-homoserine lactone quorum sensing in Gram-negative bacteria: a signaling mechanism involved in associations with higher organisms. Proceedings of the National Academy of Sciences (USA) 97, 8789-8793

Passador, L., Cook, J.M., Gambello, M.J., Rust, L. and Iglewski, B.H. (1993) Expression of Pseudomonas aeruginosa virulence genes requires cell-to-cell communication. Science 260, 1127-1130

Pearson, J.P., Gray, K.M., Passador, L., Tucker, K.D., Eberhard, A. et al. (1994) Structure of the autoinducer required for expression of $P$. aeruginosa virulence genes. Proceedings of the National Academy of Sciences (USA) 91, 197-201

Pearson, J.P., Passador, L., Iglewski, B.H. And Greenberg, E.P. (1995) A second $N$-acyl homoserine lactone signal produced by Pseudomonas aeruginosa. Proceedings of the National Academy of Sciences (USA) 92, 1490-1494

Pearson, J.P., Pesci, E.C. And Iglewski, B.H. (1997) Roles of Pseudomonas aeruginosa las and rhl quorum-sensing systems in control of elastase and rhamnolipid biosynthesis genes. Journal of Bacteriology 179, 5756-5767

Pesci, E.C., Milbank, J.B., Pearson, J.P., Mcknight, S., Kende, A.S. et al. (1999) Quinolone signaling in the cell-to-cell communication system of Pseudomonas 
aeruginosa. Proceedings of the National Academy of Sciences (USA) 96, 1122911234

Pierson, L.S., KepPenne, V.D. And Wood, D.W. (1994) Phenazine antibiotic biosynthesis in Pseudomonas aureofaciens is regulated by $\mathrm{PhzR}$ in response to cell density. Journal of Bacteriology 176, 3966-3974

PInZON, N.M. AND Ju, L.K. (2009) Analysis of rhamnolipid biosurfactants by methylene blue complexation. Applied Microbiology and Biotechnology 82, 975-981

Rahim, R., Ochsner, U.A., Olvera, C., Graninger, M., Messner, P. et al. (2001) Cloning and functional characterization of the Pseudomonas aeruginosa rhlC gene that encodes rhamnosyltransferase 2, an enzyme responsible for dirhamnolipid biosynthesis. Molecular Microbiology 40, 708-718

Rahman, K.S.M., Rahman, T.J., Mcclean, S., Marchant, R. and Banat, I.M. (2002) Rhamnolipid biosurfactant production by strains of Pseudomonas aeruginosa using low-cost raw materials. Biotechnology Progress 18, 1277-1281

Rahman, K.S.M., Rahman, T.J., Kourkoutas, Y., Petsas, I., Marchant, R. et al. (2003) Enhanced bioremediation of n-alkanes in petroleum sludge using bacterial consortium amended with rhamnolipid and micronutrients. Bioresource Technology 90, 159-168

Rahman, K.S.M. and GaKPe, E. (2008) Production, characterization and applications of biosurfactants - Review. Biotechnology 7, 360-370

Rendell, N.B., Taylor, G.W., Somerville, M., Todd, H., Wilson, R. et al. (1990) Characterization of Pseudomonas rhamnolipids. Biochimica Biophysica Acta 1045, 189-193

Robert, M., Mercade, M.E., Bosch, M.P., Parra, J.L., Espuny, M.J. et al. (1989) Effect of carbon source on biosurfactant production by Pseudomonas aeruginosa 44T1. Biotechnology Letters 11, 871-874

RosenBERG, E. AND Ron, E.Z. (1999) High and low molecular mass microbial surfactants. Applied Microbiology and Biotechnology 52, 154-162

Rumbaugh, K.P., Griswold, J.A. And Hamood, A.N. (2000) The role of quorum sensing in the in vivo virulence of Pseudomonas aeruginosa. Microbes and Infection 2 , 1721-1731

Sauer, K., Camper, A.K., Ehrlich, D., Costerton, J.W. and Davies, D.G. (2002) Pseudomonas aeruginosa displays multiple phenotypes during development as a biofilm. Journal of Bacteriology 184,1140-1154

Schauder, S., Shokat, K., Surette, M.G. and Bassler, B.L. (2001) The LuxS family of bacterial autoinducers: biosynthesis of a novel quorum-sensing signal molecule. Molecular Microbiology 41, 463-476

Shrout, J.D., Chopp, D.L., Just, C.L., Hentzer, M., Givskov, M. et al. (2006) The impact of quorum sensing and swarming motility on Pseudomonas aeruginosa is nutritionally conditional. Molecular Microbiology 62, 1264-1277

SiEGMund, I. AND WaGnER, F. (1991) New method for detecting rhamnolipids excreted by Pseudomonas species during growth on mineral agar. Biotechnology Techniques 5, 265-268

Sim, L., WARD, O.P. AND Li, Z.Y. (1997) Production and characterization of a biosurfactant isolated form Pseudomonas aeruginosa UW-1. J Ind Microbiol Biotechnol 19, 232-238.

Singh, P.K., Schaefer, A.L., Parsek, M.R., Moninger, T.O., Welsh, M.J. et al. (2000) 
Quorum-sensing signals indicate that cystic fibrosis lungs are infected with bacterial biofilms. Nature 407, 762-764

SMith, R.S. And IGLewski, B.H. (2003) P. aeruginosa quorum-sensing systems and virulence. Current Opinion in Microbiology 6, 56-60

Sotirova, A.V., Spasova, D.I., Vasileva-tonkova, E. and Galabova, D.N. (2007) Effects of rhamnolipid-biosurfactant on cell surface of Pseudomonas aeruginosa. Microbiology Research 164, 297-303

Sotirova, A.V., Spasova, D.I., Galabova, D.N., Karpenko, E. and Shulga, A. (2008) Rhamnolipid biosurfactant permeabilizing effects on Gram positive and Gram negative bacterial strains. Current Microbiology 56, 639-644

StAnghellini, M.E. AND Miller, R.M. (1997) Biosurfactants: their identity and potential efficacy in the biological control of zoosporic plant pathogens. Plant Disease 81, 4-12

Stanghellini, M.E., Miller, R.M., Rasmussen, S.L., Kim, D.H. And Zhang, Y. (1998) Microbially produced rhamnolipids (biosurfactants) for the control of plant pathogenic zoosporic fungi. United States Patent 5767090

Syldatk, C., Lang, S., Matulovic, U. and Wagner, F. (1985) Production of four interfacial active rhamnolipids from $n$-alkanes or glycerol by resting cells of Pseudomonas aeruginosa species DSM 2874. Z Naturforsch C 40, 61-67

TATJANA, P. AND GoRAn, P. (2007) Use of rhamnolipids in wound healing, treating burn shock, atherosclerosis, organ transplants, depression, schizophrenia and cosmetics. US Patent 7262171

Toder, D.S., Gambello, M.J. And Iglewski, B.H. (1991) Pseudomonas aeruginosa LasA: a second elastase gene under transcriptional control of LasR. Molecular Microbiology 5, 2003-2010

Toder, D.S., Ferrell, S.J., Nezezon, J.L., Rust, L. And Iglewski, B.H. (1994) lasA and las $B$ genes of Pseudomonas aeruginosa: analysis of transcription and gene product activity. Infection and Immunity 62, 1320-1327

Tremblay, J., Richardson, A.P., Lepine, F. and Deziel, E. (2007) Self-produced extracellular stimuli modulate the Pseudomonas aeruginosa swarming motility behaviour. Environmental Microbiology 9, 2622-2630

Tu, K.C., Waters, C.M., Svenningsen, S.L. And Bassler, B. (2008) A small RNAmediated feedback loop controls quourm-sensing dynamics in Vibrio harveyi. Molecular Microbiology 70, 896-907

Tuleva, B.K., Ivanov, G.R. And Christova, N.E. (2002) Biosurfactant production by a new Pseudomonas putida strain. Z Naturforsch C 57, 356-360

Tummler, B., Koopmann, U., Grothues, D., Weissbrodt, H., Steinkamp, G. et al. (1991) Nosocomial acquisition of Pseudomonas aeruginosa by cystic fibrosis patients. Journal of Clinical Microbiology 29, 1265-1267

Urum, K., Grigson, S., Pekdemir, T. and Mcmenamy, S. (2006) A comparison of the efficiency of different surfactants for removal of crude oil from contaminated soils. Chemosphere 62, 1403-1410

Van dyke, M.I., Couture, P., Brauer, M., Lee, H. And Trevors, J.T. (1993) Pseudomonas aeruginosa UG2 rhamnolipid biosurfactants: structural characterization and their use in removing hydrophobic compounds from soil. Canadian Journal of Microbiology 39, 1071-1078

Van haesendonck, Ingrid paula, H., Van zeveren, Emmanuel claude, A.L.B. (2004) 
Rhamnolipids in bakery products PURATOS NV (BE) EP1415538.

Volkering, F., Breure, A.M., Van Andel, J.G. And Rulkens, W.H. (1995) Influence of nonionic surfactants on bioavailability and biodegradation of polycyclic aromatic hydrocarbons. Applied and Environmental Microbiology 61, 1699-1705

WANG, D., Ding, X. AND RATHER, P.N. (2001) Indole can act as an extracellular signal in Escherichia coli. Journal of Bacteriology 183, 4210-4216

Wang, X., Gong, L., Liang, S., Han, X., Zhu, C. et al. (2005) Algicidal activity of rhamnolipid biosurfactants produced by Pseudomonas aeruginosa. Harmful Algae 4, 433-443

Wang, Q.H., FAng, X., Bai, B.J., Liang, X.L., Shuler, P.L. et al. (2007) Engineering bacteria for production of rhamnolipid as an agent for enhanced oil recovery. Biotechnology and Bioengineering 98, 842-853

Waters, C.M. AND BASSLER, B.L. (2005) Quorum sensing: cell-to-cell communication in bacteria. Annual Reviews in Cell Developmental Biology 21, 319-346

Whitehead, N.A., Barnard, A.M., Slater, H., Simpson, N.J. and Salmond, G.P. (2001) Quorum-sensing in gram-negative bacteria. FEMS Microbiology Review 25, 365-404

Wienholds, E. ANd Plasterk, R.H. (2005) MicroRNA function in animal development. FEBS Letters 579, 5911-5922

Williams, P., Winzer, K., Chan, W.C. and Camara, M. (2007) Look who's talking: communication and quorum sensing in the bacterial world. Philosophical Transactions of the Royal Society London B: Biological Sciences 362, 1119-1134

Williams, P. And CAmara, M. (2009) Quorum sensing and environmental adaptation in Pseudomonas aeruginosa: a tale of regulatory networks and multifunctional signal molecules. Current Opinion in Microbiology 12,182-91

Winson, M.K., Camara, M., Latifi, A., Foglino, M., ChHabra, S.R. et al. (1995) Multiple $\mathrm{N}$-acyl-Lhomoserine lactone signal molecules regulate production of virulence determinants and secondary metabolites in Pseudomonas aeruginosa. Proceedings of the National Academy of Sciences (USA) 92, 9427-9431

Wu, J.Y., YeH, K.L., Lu, W.B., Lin, C.L. AND ChANG, J.S. (2008) Rhamnolipid production with indigenous Pseudomonas aeruginosa EM1 isolated from oil-contaminated site. Bioresource Technology 99, 1157-1164

You, L., Cox, R.S., Weiss, R. ANd ARnold, F.H. (2004) Programmed population control by cell-cell communication and regulated killing. Nature 428, 868-871

Zhang, Y. And MiLler, R.M. (1994) Effect of a Pseudomonas rhamnolipid biosurfactant on cell hydrophobicity and biodegradation of octadecane. Applied and Environmental Microbiology 60, 2101-2106

Zhang, Y. AND Miller, R.M. (1995) Effect of rhamnolipid (biosurfactant) structure on solubilization and biodegradation of n-alkanes. Applied and Environmental Microbiology 61, 2247-2251

Zulianello, L., Canard, C., Kohler, T., Caille, D., Lacroix, J.S. et al. (2006) Rhamnolipids are virulence factors that promote early infiltration of primary human airway epithelia by Pseudomonas aeruginosa. Infection and Immunity 74, 3134-3147 